\title{
Perceived threats towards COVID-19 pandemic among Nepali migrant workers returned from India
}

\author{
Shanti Prasad Khanal*1, Edwin van Teijlingen², Mohan Kumar Sharma ${ }^{3}$, \\ Jib Acharya ${ }^{4}$, Chhabita Sharma ${ }^{5}$
}

${ }^{1}$ Health and Population Education Department, University Campus, TU., Kirtipur

${ }^{2}$ Bournemouth University, Bournemouth Gateway Building (5th floor), St Paul's Lane,

Bournemouth, BH8 8GP, United Kingdom

${ }^{3}$ Graduate School of Education (PhD Scholar), TU

${ }^{4}$ Business Development and Research Manager. ANC Premium Services Ltd./Bournemouth University

${ }^{5}$ Midwestern University, Surkhet

*Corresponding author: khanalshanti100@gmail.com; ORCID Id https://orcid.org/0000-0001$6001-9502$

\begin{abstract}
Evidence shows that the seasonal migrants returned from India have been a source of COVID-19, which helped spread it across Nepal. This cross-sectional study, guided by the Health Belief Model (HBM) model, that people's underlying believes in this case around COVID-19, is determined by a large extend their subsequent behaviors. This study aimed to examine the association between personal characteristics and perceived threats regarding COVID-19 among 384 seasonal migrants who had returned from India and were staying in a quarantine center in Surkhet, Nepal. A questionnaire was used with the help of three health workers working in the Quarantine Center. A five-point sequential grade Likert scale was constructed based on two HBM constructs, like 'perceived susceptibility' and 'severity.' A score $\geq$ of $50 \%$ was designated as high, and $\leq 50 \%$ as a perceived low level of threat. Univariate and bivariate analyses were performed to interpret the data using SPSS 20 version. Generally, participants regarded the threat of COVID-19 as low. The severity of COVID-19 was thought to be greater than the vulnerability of the subjects. Gender, age, caste, education, health status, and perceived susceptibility did not correlate with perceived susceptibility. However, the participants' demographic characteristics were associated with their perceived level of severity. Therefore, this study calls for proper risk communication to people who returned from abroad, as this is essential in promoting protective behavior during a pandemic outbreak.
\end{abstract}

Keywords: COVID-19, cross-sectional design threat, perception, personal characteristics, seasonal-migrants 


\section{INTRODUCTION}

Coronavirus (COVID-19) pandemic is a humanitarian emergency (Hua \& Shaw, 2020) that originated from the Hubei province of China in late 2019. The first case of COVID-19 in Nepal was detected on January 23, 2020, when a 32-year-old Nepali man returned from Wuhan (Ministry of Health and Population, 2020). When this article was written, more than 784,566 cases have been tested positive, and 110,40 people died from the pandemic (Ministry of Health and Population, September 19, 2021). COVID-19 is spreading at an unprecedented rate, putting people at high risk in low-income countries like Nepal. The current COVID-19 risk communication strategies are lacking in knowledge and misunderstanding (Gautam, 2020).

Misinformation, misunderstanding, and awareness in the population vary significantly. This can result in rapid transmission of infection in the community. The knowledge and perception about the safety precaution during the pandemic outbreak among adults in the general population have been measured (D. R. Singh et al., 2020), but not yet in migrant workers traveling back from India. The COVID-19 pandemic is associated with low-risk perception. If some of the population perceived it to be of lower risk, these people might impose negative externalities on others in their community. Perceptions of the risks are a key component of behavioral change theories (Barrios \& Hochberg, 2020). The risk perception was positively associated with the following variables, i.e., age, knowledge, and preventive behaviors.

Moreover, to be saved from COVID-19, proper risk communication is critical to encourage protective behaviors (Asefa et al., 2020). Intensive awareness campaigns, guidelines, education, and training should be rolled out using multifaceted public health strategies, regular monitoring, review of practices, and feedback (Asim et al., 2020). The World Health Organization (2019) suggested that keeping physical distance, wearing a mask, keeping rooms well ventilated, avoiding crowds, hand washing, and covering the face while coughing are the key measures of protecting the community from COVID-19. As per WHO guidelines, the Government of Nepal has also taken some preventive steps to prevent the transmission of COVID-19. Due to its high population density, poor protective behavior, and low awareness rate, Nepal is also a vulnerable country to a pandemic (Asim et al., 2020).

Thousands of migrant workers came home after India's coronavirus-induced lockout (Business Standard, September 6, 2020). It is estimated that 10,4 million labor migrants returned to their homes during this period (Singh et al., 2020). The imposition of nationwide lockdowns in India and Nepal severely impacted migrants and revealed some complicated cross-border dynamics (Baniya et al., 2020). This situation made migrant workers more susceptible to infection (International Labour Organization, 2020). The mass of migrants work in the informal sector, crossing the open border into India to work there, and this group has shown increased mobility in the wake of the COVID-19 incident (Singh et al., 2020). India is the most popular destination for people from provinces five and seven. More than 900,000 Nepalese have gone to India for work, and 151,590 people migrated from the Karnali Province (CBS \& ILO, 2019). Among them, 96,549 (63.3\%) ended up in India (Baniya et al., 2020). Nepal faces serious challenges due to the thousands of Nepali migrant workers being forced to return home because of COVID-19, with the hardest-hit pandemic most susceptible to the pandemic (Chalise, 2020; Shivakoti, 2020). In Nepal, the Karnali province is the most susceptible to the pandemic (Chalise, 2020).

The studies mentioned above revealed that migrants are most vulnerable and many of them are spreading COVID-19 to their hometowns, increasing cases in selected areas. To our knowledge, 
there have been few studies on so-called threats perception among migrant populations. The magnitude and importance of the threat are defined as perceived severity, while perceived susceptibility to the threat is defined as one's perception of the likelihood of experiencing the threat (Weinstein, 2001). Thus, this research paper goals to examine the association between personal characteristics and perceived threats regarding COVID-19 among Nepali Migrant workers.

\section{Theoretical framework}

The Health Belief Model (HBM), one of the most widely used conceptual models in health behavior studies, was adopted for this study (Glanz et al., 2008). This model predicts a person's action, including change behavior, based on evaluating several constructs such as perceived susceptibility, seriousness, benefits and barriers to a behavior, cues to action, and self-efficacy (Fertman \& Grim, 2010; Glanz et al., 2008). Among those six constructs, only two, perceived susceptibility and severity of COVID-19, were a theoretical guideline for this study. Individuals' perceptions of the threat's magnitude and importance are known as perceived severity, whereas their perceptions of their chance of being affected by the threat are perceived susceptibility to the threat (Kuang, 2020). The person decides if he or she is susceptible (perceived susceptibility) to a disease or condition and weighs this against the severity of the disease or condition (perceived severity) (Fertman \& Grim, 2010). In the present study, gender, caste, age, education, and health status were included under the modifying factor and perceived susceptibility and severity have been included as individual health behavior and belief about the COVID-19. The health belief model was one of the old models to apply the premise that health behaviors are motivated by the degree of fear (perceived health threat) (McKellar \& Sillence, 2020). Fear appeals, also known as belief regarding potential danger, have long been used to encourage people to engage in prescribed preventive activities (Stolow et al., 2020). Fear appeals with high susceptibility and severity successfully change people's minds and intentions (Tannenbaum et al., 2015). If a person senses a threat to their health and is repeatedly prompted to take action, and the perceived benefits outweigh the perceived barriers, they are more likely to take the advised preventive health activity (McKellar \& Sillence, 2020). Therefore, to find out the beliefs mentioned above related to COVID-19, this study has covered two key constructs of the HBM model.

\section{MATERIALS AND METHODS}

\section{Research design and sample population}

This cross-sectional study was carried out among 384 Nepali seasonal migrants aged 16 and over, who returned from India and stayed in the Quarantine Centre at Birendranagar, Surkhet of Nepal, between July and October 2020. The study followed the purposive sampling technique. The study recruited three health workers from the government health network. They were given three hours of theoretical and practical training on research methodology such as data collection, ethical issues, confidentiality and recording the data efficiently and effectively.

\section{Data collection tools}

The study followed quantitative questionnaire as a key tool. The questionnaire was used to collect demographic data and health-seeking behaviors of the participants. Similar tools were not available in Nepal, which was validated in the past. A Likert-type scale was used to collect data related to the perception of risk. Based on constructs (perceived susceptibility and severity) of the HBM, ten items were created. For all the responses, there were five sequential 
grades/close-ended questions were utilized, such as strongly agree, agree, undecided, disagree, and strongly disagree. The total scores of responses were converted into a percentile form. The scores of perceived level of belief or susceptibility and severity of $>50) \%$ were taken down as a high and $\leqq 50 \%$ as a low.

\section{Reliability of the study}

The Cronbach's alpha coefficient was used to determine the questionnaire's reliability. (Tavakol $\&$ Dennick, 2011). The value of Likert scale items was 0.80 . After the pretest, two items from the Likert scale were eliminated. A pilot study (van Teijlingen \& Hundley, 2001) was carried out with the 12 participants and those pretest participants were not included in the main study to avoid contamination of the sample.

We simply obtained approval to conduct this study from the health service department of the Ministry of Social Development of the Karnali province and Birendranagar Municipality. Before administration of the tool, verbal consent from each participant was obtained. Anonymity and confidentiality of their information were strictly maintained and participation was voluntary.

\section{Statistical test}

SPSS V.20 had been used for statistical analysis at the 5\% significance level (Coakes, 2012). The data were examined using descriptive and inferential statistics. The frequencies and percentages were computed for categorical variables firstly. To determine the threat perception level, the responses' total scores were converted to percentiles. Scores of $>50 \%$ ) percent for a perceived level of belief or susceptibility and severity were considered high, whereas scores of less than 50\% were considered low. Cross-tabulation and Pearson's chi-square test was used in bivariate analysis to examine the association between independent and dependent variables.

\section{RESULTS}

\section{Participants' characteristics}

Table 1 shows most participants (74\%) were male, $67.2 \%$ were between 20 and 39 years of age, Chhetri (41.1\%), Dalit (33.3\%) and literate (35.7\%). Overall, most of the participants said that their health was normal $(80.7 \%)$. Only a small proportion $(9.9 \%)$ were younger than 20 had migrated to India for work.

Table 1: Demographics of participants $(n=384)$

\begin{tabular}{llcc}
\hline Demographic profile & \multicolumn{1}{c}{ Category } & Frequency & Percent \\
\hline Gender & Male & 284 & 74.0 \\
& Female & 100 & 26.0 \\
Age (in years) & Total & 384 & 100.0 \\
& Below 20 & 38 & 9.9 \\
& $20-39$ & 258 & 67.2 \\
& $40-59$ & 76 & 19.8 \\
& $60+$ & 12 & 3.1 \\
& Total & 384 & 100.0 \\
\hline
\end{tabular}




\begin{tabular}{llcc}
\hline Caste & Chhetri & 158 & 41.1 \\
& Brahmins & 48 & 12.5 \\
Janajati & 50 & 13.0 \\
Education & Dalit & 128 & 33.3 \\
& Total & 384 & 100.0 \\
& Literate & 137 & 35.7 \\
& Illiterate & 48 & 12.5 \\
& Basic & 68 & 17.7 \\
Health status & Secondary & 75 & 19.5 \\
& Higher & 27 & 7 \\
& Total & 384 & 100.0 \\
& Normal & 310 & 80.7 \\
& Acute & 47 & 12.2 \\
& Chronic & 27 & 7.0 \\
& Total & 384 & 100.0 \\
\hline
\end{tabular}

Note: Normal; healthy, Acute; poor health condition, Chronic; suffered from a chronic problem

\section{Perceived threats}

Table 2 shows the level of perceived threats, including perceived susceptibility and severity to COVID-19. Looking at the result, the overall level of perceived threat is low, whilst some participants seem to have a higher level of perceived severity than the susceptibility. There does not seem to be a correlation between participants' level of perceived susceptibility and severity. Only one respondent did not record severity and none of them missed out on recording susceptibility.

Table 2: Level of perceived threats and correlation between perceived susceptibility and severity

\begin{tabular}{lcccc}
\hline Susceptibility & \multicolumn{3}{c}{ Severity } & $(\%)$ \\
Level & Frequency & $(\%)$ & Frequency & 59.8 \\
Low & 332 & 86.5 & 229 & 40.2 \\
High & 52 & 13.5 & 154 & 0.3 \\
No & 0 & 0 & 1 & 100 \\
response & & & 384 & \\
Total & 384 & 100.0 & 38 & \\
\hline
\end{tabular}

\section{Association between participants' characteristics and perceived threats}

Table 3 explores the associations between demographic characteristics and perceived susceptibility to COVID-19. Participants of both genders had an equally low perception of their susceptibility. Similarly, all age groups have a higher level of perception in susceptibility (Table 3) than of severity (Table 4). People in the 40-59 age group seemed to perceive susceptibility than the other age groups better. Most young people (94\%) under the age of 20 had a low level of perceived susceptibility, but these young people had the highest (52\%) level of perception of the severity of all age groups. 
Similarly, people of all castes had a lower-level perception of susceptibility than the severity. Although, higher caste Brahmin reported a higher perception level of severity than other castes.

Table 3: Association between participants' characteristics and perceived susceptibility

\begin{tabular}{|c|c|c|c|c|c|}
\hline \multirow{2}{*}{ Demographic profile } & \multirow[t]{2}{*}{ Categories } & \multicolumn{2}{|c|}{$\begin{array}{l}\text { Perceived } \\
\text { susceptibility }\end{array}$} & \multirow[b]{2}{*}{ Total } & \multirow{2}{*}{$\begin{array}{l}\text { Pearson } x^{2} \text { test } \\
\text { Asymp. Sig. } \\
\text { sided) }\end{array}$} \\
\hline & & Low & High & & \\
\hline \multirow[t]{2}{*}{$\overline{\text { Sex }}$} & Male & $85.2 \%$ & $14.8 \%$ & $100.0 \%$ & $* *$ \\
\hline & Female & $90.0 \%$ & $10.0 \%$ & $100.0 \%$ & \\
\hline \multirow[t]{4}{*}{ Age (in years) } & Below 20 & $94.7 \%$ & $5.3 \%$ & $100.0 \%$ & $*$ \\
\hline & $20-39$ & $86.8 \%$ & $13.2 \%$ & $100.0 \%$ & \\
\hline & $40-59$ & $78.9 \%$ & $21.1 \%$ & $100.0 \%$ & \\
\hline & $60+$ & $100.0 \%$ & - & $12 \% ?$ & \\
\hline \multirow[t]{4}{*}{ Caste } & Chhetri & $82.3 \%$ & $17.7 \%$ & $100.0 \%$ & $* *$ \\
\hline & Brahmins & $83.3 \%$ & $16.7 \%$ & $100.0 \%$ & \\
\hline & Janajati & $88.0 \%$ & $12.0 \%$ & $100.0 \%$ & \\
\hline & Dalit & $92.2 \%$ & $7.8 \%$ & $100.0 \%$ & \\
\hline \multirow[t]{5}{*}{ Educational status } & Literate & $88.7 \%$ & $11.3 \%$ & $100.0 \%$ & $* *$ \\
\hline & Illiterate & $81.1 \%$ & $18.9 \%$ & $100.0 \%$ & \\
\hline & Basic & $90.0 \%$ & $10.0 \%$ & $100.0 \%$ & \\
\hline & Secondary & $84.3 \%$ & $15.7 \%$ & $100.0 \%$ & \\
\hline & Higher & $81.5 \%$ & $18.5 \%$ & $100.0 \%$ & \\
\hline \multirow[t]{3}{*}{ Health status } & Normal & $85.2 \%$ & $14.8 \%$ & $100.0 \%$ & $* *$ \\
\hline & Acute & $93.6 \%$ & $6.4 \%$ & $100.0 \%$ & \\
\hline & Chronic & $88.9 \%$ & $11.1 \%$ & $100.0 \%$ & \\
\hline
\end{tabular}

Note: Chi-square test significant at $*=p<0.05 / * *=p<0.05$

Statistically, there is no association seen between the participants' profile and their perceived susceptibility. The perceived level of susceptibility is not differing significantly between all educated and illiterate groups, but people with basic education have a more perceived level of severity than the other groups. People with chronic illness score significantly lower than either healthy people or people with acute health conditions (Table 3 ).

Table 4: Association between participants' demographics and perceived severity

\begin{tabular}{|c|c|c|c|c|c|c|}
\hline \multirow{2}{*}{$\begin{array}{l}\text { Demographic } \\
\text { profiles }\end{array}$} & \multirow[b]{2}{*}{ Category } & \multicolumn{3}{|c|}{ Perceived severity } & \multirow[b]{2}{*}{ Total } & \multirow{2}{*}{$\begin{array}{l}\text { Pearson } \mathrm{x}^{2} \text { test } \\
\text { Asymp. Sig. } \\
\text { sided) }\end{array}$} \\
\hline & & Low & High & $\begin{array}{c}\text { no } \\
\text { response }\end{array}$ & & \\
\hline \multirow[t]{2}{*}{ Sex } & Male & $59.7 \%$ & $40.3 \%$ & 0.3 & $100.0 \%$ & $* *$ \\
\hline & Female & $60.0 \%$ & $40.0 \%$ & 0.3 & $100.0 \%$ & \\
\hline \multirow[t]{2}{*}{ Age } & Below 20 & $47.4 \%$ & $52.6 \%$ & 0.3 & $100.0 \%$ & $*$ \\
\hline & $20-39$ & $55.6 \%$ & $44.4 \%$ & 0.3 & $100.0 \%$ & \\
\hline
\end{tabular}




\begin{tabular}{llllll}
\hline \multirow{5}{*}{ Caste } & $40-59$ & $76.3 \%$ & $23.7 \%$ & 0.3 & $100.0 \%$ \\
& $60+$ & $83.3 \%$ & $16.7 \%$ & 0.3 & $100.0 \%$ \\
& Chhetri & $59.5 \%$ & $40.5 \%$ & 0.3 & $100.0 \%$
\end{tabular}

Note: Chi-square test significant at $*=\mathrm{p}<0.05 * *=\mathrm{P}<0.005$

Table 4 reflects that the participants' demographic profiles that affect their perceived severity and gender and educational status do not affect the perceived severity of the participants.

\section{DISCUSSION}

This study examined the association between socio-demographic factors and the perceived threat to COVID-19 among Nepalese seasonal migrant workers who returned from India and stayed at least ten days in the quarantine center in Surkhet, the western part of Nepal. Despite the increasing problem of COVID-19, the present study's findings indicated that the overall level of perceived risks was relatively low (susceptibility, $86.5 \%$ and severity, 59.8\%), it could be due to the control of the quarantine center where all the precautions were compulsorily taken by the clients. On the other hand, all the migrants were not fully aware of the issue. The migrants had a poor perception of threats concerning COVID-19. There might be other detrimental factors such as low education, poor health literacy, poor awareness about the disease, unavailability of resources to cause them low-level threat perception of the disease. This finding is contradictory with the finding of a study in 2021 in Kerala (India), which reported the perceived susceptibility was higher (65.4\%) and the perceived severity was lower $(44.3 \%)$ (Jose et al., 2021). Similar research conducted in Mexico in 2020 stated that more than half $(54.2 \%)$ of elderly participants perceived their susceptibility to COVID-19 to be very poor. However, $33.4 \%$ of participants perceived the severity of COVID-19 to be very low (IrigoyenCamacho et al., 2020). Although, our study reported that some participants seem to have a higher level of severity (40.2\%) than susceptibility (13.5\%). Reasons for the contradictory finding than others might have been due to the lower education, marginalized and working-class participants (Table 1). According to the HBM, individual elements are an important determinant of threat perception (Weinstein, 2001). On the other hand, the social model focuses on multiple influences on threat perception among individuals, groups, and their environments (Wharf Higgins et al., 2009). The study results correspondingly found no association between participants' level of perceived susceptibility and severity (Table 2). There were more significant variations between the groups in the dimensions of perceived susceptibility and 
severity (Costa, 2020). A comparative study conducted in 2020 among the general population in Saudi Arabia, Egypt, and Jordan found that the perception of COVID-19 was significantly higher among the participants from Saudi Arabia and the perception of susceptibility to COVID-19 among the Saudi Arabians was also scored highly compared to Egypt and Jordan (Shahin \& Hussien, 2020). Several researchers have illustrated that most people whether from developing countries like Nepal or developed countries like the USA and UK are highly fearful of the outbreak (Karn et al., 2020). A study conducted on risk perception towards the COVID19 and its associated factors among waiters in selected towns of Southwest Ethiopia had a more excellent risk perception of the COVID-19, and this risk perception was also related to age (Asefa et al., 2020). A study on public risk perception of COVID-19 across ten countries in Europe, America and Asia in 2020 reported that levels of concern are relatively high and highest in the U.K. compared to all sampled countries (Dryhurst et al., 2020). With a more rigorous application, the HBM can help us understand people's beliefs toward the susceptibility and severity of COVID-19.

Self-reported data showed that an increase in susceptibility and a decrease in severity were related to a gradual increase in perceptions of health risk prevalence rates (El-Toukhy, 2015). Perceived susceptibility and severity are combined to identify a threat. The least effective predictor of preventive health behavior was overall perceived severity, while the perceived vulnerability was the strongest (Champion \& Skinner, 2008). Perceptions of susceptibility and severity are noticeably, but not entirely, independent (Cummings et al., 1978). The finding of this study does not coincide with the study by Morovati et al. (2007). Our study found no meaningful association between the perceived susceptibility and severity among the participants about the COVID-19. Another study has also come up with a different finding than this study, which has a moderate positive correlation between perceived susceptibility and severity, suggesting that while these are different concepts, they overlap to some extent (Cummings et al., 1978). A study conducted in Iran found that the perceived susceptibility and others were predictors of water conservation behavior and perceived severity, and other constructs had no influence on behavior (Tajeri Moghadam et al., 2020).

These outcomes are not surprising. Apart from risk perceptions, there are plenty of other variables also involved (Weinstein, 2001). The research conducted by Jahangiry and colleagues suggests that socioeconomic and demographic factors are the main determinants of the COVID19 risk perception (Jahangiry et al., 2020). Niño et al. (2021) found that ethnicity, gender, and age play a crucial role in shaping COVID-19 threat and fear perceptions. Coronavirus is more likely to be feared by racial and ethnic minorities, and they are more likely to perceive it as a significant threat to the population and individual health. Women are more likely to feel frightened than men about COVID-19. In general, it is seen as a high-risk virus by older age groups. Finally, there is a strong age correlation with older adults reporting that COVID-19 poses a higher risk. A study conducted in Nigeria found that older age predicted risk perception, but gender did not predict it.

Furthermore, risk perception was found to moderate the association between COVID-19 knowledge and precautionary behavior (Iorfa et al., 2020). Another study from Spain found a significant relationship between socio-demographic factors and risk perception (Mansilla Domínguez et al., 2020). An online study in Nepal in 2020 noted that the perceived risk of COVID-19 was high for health workers (Sharma et al., 2020). 
While Nepal is witnessing the $2^{\text {nd }}$ phase of COVID -19 , and many of those returning from India also have been infected/ and affected, there is a need for developing effective intervention approaches to prevent the spread of such infection. More important, there is a need for appropriate awareness-raising programs at the point of entry, COVID-19 safe quarantine management, and consistent public health orders so on. Moreover, people who perceive a low risk of COVID-19 are more likely to spread it to other people without taking protective measures. While writing this paper, the second phase of COVID-19 is spreading in India. This may result in more Nepali workers returning home. The finding of the study may imply applying the program to change health behavior by fear appealing for those people. Therefore, a useful intervention to help prevent the spread of COVID-19 might be health promotion attempts to increase the level of threat perception of the pandemic through risk communication.

\section{Limitations}

This study has perceived some limitations. First, in this study, the health belief model was used to focus on only two constructs: perceived susceptibility and severity. Secondly, not all migrant workers spend time in a quarantine center on return, limiting the generalizability to the whole migrant population. Thirdly, the nature of the questionnaire with given multiple answers means participants could not share their views or ideas. Fourthly, because of the lockdown in Nepal, the first authors could not be involved in the data collection process and lastly, only one study site/Surkhet findings may not be generalizable to other parts of Nepal.

\section{CONCLUSION}

The findings of this study conclude that there is no association seen between the participants' demographic variables and the perceived susceptibility. However, the age, caste, and educational status of the participants affect the perceived severity level of the participants. There is a need for developing effective intervention approaches to increase threat perception to prevent the spread of COVID-19. More important, appropriate awareness-raising initiatives are required. At the point of entry, COVID-safe quarantine management, and consistent public health order so on. Therefore, this study calls for proper risk communication to people who returned from abroad, which is essential in promoting protective behavior during a pandemic. 


\section{REFERENCES}

Asefa, A., Qanche, Q., Hailemariam, S., Dhuguma, T., Nigussie, T., \& Policy, H. (2020). Risk perception towards covid-19 and its associated factors among waiters in selected towns of southwest Ethiopia. Risk Management and Healthcare Policy, 13, 2601-2610. doi: https://doi.org/10.2147/RMHP.S276257

Asim, M., Sathian, B., van Teijlingen, E., Mekkodathil, A., Subramanya, S. H., \& Simkhada, P. (2020). Covid-19 pandemic: Public health implications in Nepal. Nepal Journal of Epidemiology, 10(1), 817-820. doi: https://doi.org/10.3126/nje.v10i1.28269

Baniya, J., Bhattarai, S., Thapa, B. J., \& Pradhan, V. (2020). Covid-19 and Nepali labor migrants: Impacts and responses. Retrieved from https://soscbaha.org/publication/covid19-and-nepali-labour-migrants-impacts-and-responses/

Barrios, J. M., \& Hochberg, Y. (2020). Risk perception through the lens of politics in the time of the covid-19 pandemic. Retrieved from https://bfi.uchicago.edu/wpcontent/uploads/BFI_WP_202032.pdf

Business Standard. (September 6, 2020). Migrant workers from Nepal start returning to India as economy reopens. The Kathmandu Post. Retrieved from https://www.businessstandard.com/article/current-affairs/migrant-workers-from-nepal-start-returning-to-indiaas-economy-reopens-120090600276_1.html

CBS, \& ILO. (2019). Report on the Nepal labour force survey 2017/18. Retrieved from https://nepalindata.com/media/resources/items/20/bNLFS-III Final-Report.pdf

Chalise, H. N. (2020). Covid-19 situation in Nepal. Archives of Psychiatry and Mental Health, 4(1), 033-034. doi: https://doi.org/10.29328/journal.apmh.1001015

Champion, V. L., \& Skinner, C. S. (2008). The health belief model: Health behaviour and health education; theory, research, and practice. In K. Glanz, B. K. Rimer, \& K. Viswanath (Eds.), Health behavior and health education: Theory, research and practice (pp. 45-65). Jossey-Bass, San Francisco, 45-65.

Coakes, S. J. (2012). Spss version 20.0 for windows: Analysis without anguish. Retrieved from https://www.wiley.com/en-

$\mathrm{ck} /$ SPSS + Version $+20+0+$ for + Windows $\% 3 \mathrm{~A}+$ Analysis + without + Anguish-p9781118337769\#download-product-flyer

Costa, M. F. (2020). Health belief model for coronavirus infection risk determinants. Revista de saude publica, 54, 1-12.doi: https://doi.org/10.11606/s1518-8787.2020054002494

Cummings, K. M., Jette, A. M., \& Rosenstock, I. M. (1978). Construct validation of the health belief model. Health Education and Behavior, 6(4), 394-405. doi: https://doi.org/10.1177/109019817800600406

Dryhurst, S., Schneider, C. R., Kerr, J., Freeman, A. L. J., Recchia, G., van der Bles, A. M., Spiegelhalter, D., \& van der Linden, S. (2020). Risk perceptions of covid-19 around the world. Journal of Risk Research, 23(7-8), 994-1006. doi:

https://doi.org/10.1080/13669877.2020.1758193 
El-Toukhy, S. (2015). Parsing susceptibility and severity dimensions of health risk perceptions. Journal of Health Communication, 20(5), 499-511. doi: https://doi.org/10.1080/10810730.2014.989342

Fertman, C. I., \& Grim, M. (Eds.). (2010). Health promotion programs: From theory to practice. John Wiley \& Sons. Retrieved from https://www.wiley.com/enar/Health+Promotion+Programs\%3 A+From+Theory+to+Practice\%2C+2nd+Edition-p9781119163336.

Gautam, D. (2020). Nepal's readiness and response to covid-19: Key initiatives, emerging challenges and the way forward. Retrieved from https://www.preventionweb.net/files/71274 71274nepalsreadinessandresponsetopa.pdf

Glanz, K., Rimer, B. K., \& Viswanath, K. (Eds.). (2008). Health behavior and health education: Theory, research and practice. John Wiley \& Sons.

Hua, J., \& Shaw, R. (2020). Coronavirus (covid-19) infodemic" and emerging issues through a data lens: The case of China. International journal of environmental research public health, 17(7), 2309. doi: https://doi.org/10.3390/ijerph17072309

International Labour Organization. (2020). Ilo monitor: Covid-19 and the world of work. Third edition updated estimates and analysis. Retrieved from https://www.ilo.org/wcmsp5/groups/public/---dgreports/--dcomm/documents/briefingnote/wcms 743146.pdf

Iorfa, S. K., Ottu, I. F. A., Oguntayo, R., Ayandele, O., Kolawole, S. O., Gandi, J. C., Dangiwa, A. L., \& Olapegba, P. O. (2020). Covid-19 knowledge, risk perception, and precautionary behavior among Nigerians: A moderated mediation approach. 11(32), 92. doi: https://doi.org/10.3389/fpsyg.2020.566773

Irigoyen-Camacho, M. E., Velazquez-Alva, M. C., Zepeda-Zepeda, M. A., Cabrer-Rosales, M. F., Lazarevich, I., \& Castaño-Seiquer, A. (2020). Effect of income level and perception of susceptibility and severity of covid-19 on stay-at-home preventive behavior in a group of older adults in Mexico city. International Journal of Environmental Research and Public Health, 17(20), 7418. doi: https://doi.org/10.3390/ijerph17207418

Jahangiry, L., Bakhtari, F., Sohrabi, Z., Reihani, P., Samei, S., Ponnet, K., \& Montazeri, A. (2020). Risk perception related to covid-19 among the Iranian general population: An application of the extended parallel process model. BMC Public Health, 20(1), 1571. doi: https://doi.org/10.1186/s12889-020-09681-7

Jose, R., Narendran, M., Bindu, A., Beevi, N., L, M., \& Benny, P. V. (2021). Public perception and preparedness for the pandemic covid 19: A health belief model approach. Clinical Epidemiology and Global Health, 9, 41-46. doi: https://doi.org/10.1016/j.cegh.2020.06.009

Karn, A., Karn, M., Agrawal, A., Giri, P., Bohara, G., Sharma, R., Adhikari, H., \& Poudel, S. (2020). Knowledge and perception on corona virus disease 2019 (covid-19) among the general public in Nepal. International Journal of Social Sciences and Management,, 7(4), 183-190.doi: https://doi.org/10.3126/ijssm.v7i4.32475

Kuang, K. (2020). The role of interactivity in new media-based health communication: Testing the interaction among interactivity, threat, and efficacy. Technology of Health, 377-397. doi: https://doi.org/10.1016/B978-0-12-816958-2.00017-4 
Mansilla Domínguez, J. M., Font Jiménez, I., Belzunegui Eraso, A., Peña Otero, D., Díaz Pérez, D., \& Recio Vivas, A. M. (2020). Risk perception of covid-19 community transmission among the spanish population. International Journal of Environmental Research and Public Health, 17(23), 8967. doi: https://doi.org/10.3390/ijerph17238967

McKellar, K., \& Sillence, E. (2020). Chapter 2 - current research on sexual health and teenagers. In K. McKellar \& E. Sillence (Eds.), Teenagers, sexual health information and the digital age (pp. 5-23). Academic Press. doi: https://doi.org/10.1016/B978-0-12816969-8.00002-3

Ministry of Health and Poulation. (September 19 2021). Health sector response to covid-19. https://covid19. Retrieved from mohp.gov.np/covid/englishSituationReport/614712704068a_SitRep588_COVID-19_1909-2021_EN.pdf

Ministry of Health and Poulation. (2020). Health sector response to covid-19. Retrieved from https://covid19.mohp.gov.np

Morovati, S., Mohammad Ali, \& Tonekaboni, N. R. (2007). Perceived severity and susceptibility of diabetes complications and its relation to self-care behaviors among diabetic patients. J Armaghan Danesh, 12(3 ), 59-68. Retrieved from https://www.sid.ir/en/Journal/ViewPaper.aspx?ID=118226

Niño, M., Harris, C., Drawve, G., \& Fitzpatrick, K. M. (2021). Race and ethnicity, gender, and age on perceived threats and fear of covid-19: Evidence from two national data sources. SSM - Population Health, 13, 100717. doi: https://doi.org/10.1016/j.ssmph.2020.100717

Shahin, M. A. H., \& Hussien, R. M. (2020). Risk perception regarding the covid-19 outbreak among the general population: A comparative middle east survey. Middle East Current Psychiatry, 27(1), 1-19. doi: https://doi.org/10.1186/s43045-020-00080-7

Sharma, B., Shrestha, N., Gurung, N., \& Banstola, S. (2020). Perceived risk, preventive behavior and enabling environment among health workers during covid-19 pandemic in Nepal: An online survey. Journal of Gandaki Medical College-Nepal, 13(2), 153-159. doi: https://doi.org/10.3126/jgmen.v13i2.31166

Shivakoti, R. (2020). Can Nepal cope with the return of migrant workers. Retrieved from https://www.opendemocracy.net/en/author/richa-shivakoti/

Singh, D. R., Sunuwar, D. R., Karki, K., Ghimire, S., \& Shrestha, N. (2020). Knowledge and perception towards universal safety precautions during early phase of the covid-19 outbreak in Nepal. J Journal of community health, 45(5), 1116-1122. doi: https://doi.org/10.1007/s10900-020-00839-3

Singh, S. K., Mishra, N., \& Aditi. (2020). Return migration of labourers in the surge of covid-19 in India: Multidimensional vulnerability and public health challenges. MOJ Public Health 9(5), 166-173. doi: https://doi.org/10.15406/mojph.2020.09.00341

Stolow, J. A., Moses, L. M., Lederer, A. M., \& Carter, R. (2020). How fear appeal approaches in covid-19 health communication may be harming the global community. 47(4), 531-535. doi: https://doi.org/10.1177/1090198120935073 
Tajeri Moghadam, M., Raheli, H., Zarifian, S., \& Yazdanpanah, M. (2020). The power of the health belief model ( $\mathrm{hbm}$ ) to predict water demand management: A case study of farmers' water conservation in Iran. Journal of Environmental Management, 263, 110388. doi: https://doi.org/10.1016/j.jenvman.2020.110388

Tannenbaum, M. B., Hepler, J., Zimmerman, R. S., Saul, L., Jacobs, S., Wilson, K., \& Albarracín, D. (2015). Appealing to fear: A meta-analysis of fear appeal effectiveness and theories. Psychological Bulletin, 141(6), 1178-1204. doi: https://doi.org/10.1037/a0039729

Tavakol, M., \& Dennick, R. (2011). Making sense of cronbach's alpha. International Journal of Medical Education, 2, 53-55. doi: https://doi.org/10.5116/ijme.4dfb.8dfd

van Teijlingen, E. R., \& Hundley, V. (2001). The importance of pilot studies. Retrieved from http://sru.soc.surrey.ac.uk/SRU35.html s

Weinstein, N. D. (2001). Health risk appraisal and optimistic bias. In N. J. Smelser \& P. B. Baltes (Eds.), International encyclopedia of the social \& behavioral sciences (pp. 66126615). Pergamon. doi: https://doi.org/10.1016/B0-08-043076-7/03805-5

Wharf Higgins, J., Begoray, D., \& MacDonald, M. (2009). A social ecological conceptual framework for understanding adolescent health literacy in the health education classroom. American Journal of Community Psychology, 44(3-4), 350. doi: https://doi.org/10.1007/s10464-009-9270-8

World Health Organization. (2019). Coronavirus disease (covid-19) advice for the public. Retrieved from https://www.who.int/emergencies/diseases/novel-coronavirus-2019/advicefor-public 